\title{
Disease Resistance of Wheat Varieties: Can Private Varieties Withstand the Pressure?
}

\author{
William Lesser and Deepthi Elizabeth Kolady \\ Dyson School of Applied Economics and Management, Cornell University, Ithaca, NY 14853-7801, USA \\ Correspondence should be addressed to William Lesser, whl1@cornell.edu
}

Received 6 December 2010; Revised 18 March 2011; Accepted 13 April 2011

Academic Editor: Jean Paul Chavas

Copyright ( 2011 W. Lesser and D. E. Kolady. This is an open access article distributed under the Creative Commons Attribution License, which permits unrestricted use, distribution, and reproduction in any medium, provided the original work is properly cited.

\begin{abstract}
US wheat varieties are examined for differential disease resistance between public and private varieties, an issue for critics of plant intellectual property. Analysis using disease resistance rankings of wheat varieties from Kansas and Texas indicate that private varieties are as or more resistant. This finding was further confirmed with two years of Texas data. Thus, the results from the study reject the criticism of private breeding activities that they are more susceptible to disease compared to public varieties. However, private varieties resistance is incorporated from public offerings so that productive private wheat breeding is partly derivative.
\end{abstract}

\section{Introduction}

Among the issues in the ongoing debate over the application of Intellectual Property Rights (IPR) to plants is the question of the productivity of private and/or protected varieties. In a recent paper, Kolady and Lesser [1] refuted the charges of cosmetic breeding - breeding which adds no traits of agronomic value-by showing the private wheat varieties in Washington state are more productive than public ones, in counter distinction to some prior analysis. That study focused on wheat varieties because of the significant involvement of both the public and private sectors in developing varieties, thus allowing for a meaningful comparison. The significant involvement of the public sector in wheat breeding also means there is a substantial comparative variety testing program from which performance data are available. The analysis effectively focused on Plant Variety Protection (PVP) as to date relatively few wheat varieties have been patented.

The present study also focuses on wheat varieties for the same reason as the earlier analysis, the involvement of both the public and private sectors in plant breeding, as well as the availability of comparative trials. The issues examined are general as to the crop, but due to data availability they are evaluated here only for wheat. What this study adds is an evaluation of another dimension of variety performance in the form of yield stability. In particular, we examine disease and pest resistance, a key aspect of stabilizing yields. The often repeated example of poor resistance-based crop losses is that of the 1970 southern corn leaf blight. Losses were estimated at 15 percent of the US crop, or somewhere between $\$ 500$ million and 1 billion, and would have been far larger if not limited to varieties grown in the southeast [2]. Wheat for its part is susceptible to a variety of rusts and mildews as well as pest attacks (Hessian fly) which can significantly reduce yields in hard hit areas. As Duvick [3] wrote regarding wheat at a time when the corn blight experience was still fresh, "Wheats have a history of epidemics of, for example, leaf and stem rusts, in the United States as well as elsewhere. Cycles of epidemics, development and release of varieties with specific single gene resistance, increase of new races of the pathogen, and then new epidemics have been well documented." In many cases, genetic resistance is the only effective control, or at least the only economically viable control [4].

Yield is clearly an important variety dimension for any farmer, and hence breeders, and US wheat breeders have been responding with an overall average annual increase in bushels per acre of one percent over the 20 periods beginning in the mid-1970s [5]. Improved genetic materials are widely credited with contributing about half the observed 
yield increases; the remaining half is attributable to enhanced inputs, including management [6]. Yield stability is important as well, but can be subliminal to yield as a criterion particularly in the case of diseases which are rare and unpredictable even if costly when they do occur. For breeders, prioritizing multiple disease resistance in variety creation complicates and delays new releases compared to a single criterion like yield. ("Fundamental tradeoffs in breeding decisions typically involve yields, disease resistance, and quality. Gains in one area often involve losses in another." [7, page 82]). Therefore it is a legitimate question the degree to which wheat breeders emphasize disease-resistance, and particularly if the foci differs between public and private sector breeders.

On the one hand, private sector seed companies are rewarded in proportion to seed sales. That creates a direct incentive to release promising varieties capable of increasing market share. If private sector breeders must decide between emphasizing higher yielding and disease resistant varieties, as to a degree they always must, the short-term sales incentive of promoting higher yielding varieties may take precedence over more disease resistant ones. As Frey [8, page 6] notes, "Private sector [breeding] goals, however, are short-term and profit-motivated so its contribution to genepool enrichment generally will be dedicated to individual genes with IPR protection potential. General genepool enrichment for multigenic traits is high-risk and long-term in scope, and therefore, must be done by the public sector." And the Office of Technology Assessment [9, page 72] observed, "Insect resistance has not been a significant component of commercial breeding programs, and none of the new commercial wheats has resistance to Hessian fly."

Of course, the private sector also has the incentive to promote disease resistance if only to avoid a potentially reputation-damaging major disease-based crop loss. But at the margin, the private sector can have a greater incentive to emphasize yield over disease resistance compared to the public sector. Conversely, public sector breeders are not rewarded directly according to the adoption of their varieties. Thus it can be argued they have greater flexibility to hold back the release of a variety with disease resistance levels considered to be inadequate. We are therefore testing here the hypothesis that the disease resistance levels of public and private varieties are equal. As the null hypothesis, a two-tailed test is chosen because while the specification of a difference in incentives is clear, the direction of the difference is less so. This analysis is therefore an empirical one using reported rankings of disease resistance levels for individual diseases. Since the hypothesis is focused on the variety owner, the protection status of varieties is not considered. As a point of fact, most private varieties are protected while public varieties are both protected and unprotected.

It should be emphasized that the objective of this paper is a simple and narrow one, yet important. We are examining only if private commercial wheat varieties are on average equally disease resistant as those developed by the public sector. We are not considering the initial source of the disease resistance, that is, if the private sector varieties utilize disease resistance previously developed by and delivered in public sector varieties. (e.g., stripe rust resistance in the [Kansas] region leans heavily on Jagger, a public variety. Tan spot resistance is largely derived from Jagger and Karl 92, both public varieties." Personal communication, Dr. Allan Fritz, Professor of Wheat Breeding, Kansas State University. Note that the Plant Variety Protection system allows the use of protected varieties as breeding materials.) The source of disease resistance is a potentially important issue when evaluating the overall contribution of public sector breeding and, indeed, when contemplating the sustainability of productive private sector wheat breeding. The authors believe that public sector crop breeding continues to provide an important source of ingenuity and competition especially during a period of privatization. However, our objective here is much narrower as it is solely focused on the empirical question of the comparability of disease resistance rankings between public and private sector varieties.

\section{Literature Review}

The Office of Technology Assessment did note that back in the 1970s Hessian-fly-resistant wheats in Kansas and Nebraska declined to 42 percentage of acreage from 66 percent over a four-year period. But generally the literature treats the issue under study here as a component of production risk particularly as regards yield stability. Disease resistance is a component of yield stability but of course but one of multiple factors. The issue in the literature is focused on the role of yield risk reduction in farmer variety selection decisions, here limited to studies in developed countries. The focus does not imply that farmers in developing countries do not face very similar variety selection decisions as their developed country colleagues. However, exogenous factors such as seed availability, knowledge of production traits, and the availability of cash or credit can affect variety selection choices between the two groups of farmers.

The seminal study of variety adoption was done by Griliches [10] who studied the spread of hybrid corn adoption in the USA since its widespread availability in the 1930s. His analysis emphasized the importance of profitability in adoption decisions, but noted the numerous small choice factors faced by individual farmers. Barkley and Porter [11] used Kansas wheat production data to analyze farmers' variety selection criteria. They found that disease resistance (using the same 1-9 ranking scale employed here) particularly to rusts and mosaics were significant explainers of variety selection choices, but much less so than relative yields (relative to the production district means used as the unit of analysis). In their simulation, a one-point improvement (11\%) in leaf rust resistance increases statewide planted acreage in wheat by 0.33 percent. By way of comparison, a 10 percent increase in the relative yield leads to a 0.93 percent increase in planted acres in one year so in a very rough sense relative yield is three times more important in variety selection than is resistance to a single major disease.

The Barkley and Porter [11] study however is not constructed to answer the question posed here, the relative disease resistance between public and private varieties. That 
TABLE 1: Results from statewide disease resistance comparison of group means between public and private wheat varieties in Kansas (2001-2008).

\begin{tabular}{lcccc}
\hline $\begin{array}{l}\text { Type of } \\
\text { disease }\end{array}$ & Ownership & $\begin{array}{c}\text { Number } \\
\text { of } \\
\text { varieties }\end{array}$ & Mean & $\begin{array}{c}\text { Statistical } \\
\text { significance of } \\
\text { difference in } \\
\text { group means } \\
\text { (at 5\%) }\end{array}$ \\
\hline BYD & Public & 109 & 7.2 & Yes \\
WSM & Private & 65 & 6.7 & Yes \\
SBM & Public & 122 & 6.8 & Yes \\
Leaf rust & Private & 74 & 6.0 & Yes \\
Stripe & Private & 120 & 4.9 & \\
rust & Private & 72 & 3.6 & 7.4 \\
Public & 121 & 6.5 & No \\
& Private & 70 & 4.6 & Yes \\
\hline
\end{tabular}

(Source: Official Kansas State University Agricultural Experiment Station and Cooperative Extension Service Report of Progress, Kansas Performance Tests with Winter Wheat Varieties). Note that disease resistance rankings range from $1-9$, with 9 as the lowest resistance.

is because the analysis uses as the dependent variable: the share of planted area while relative yield, disease rankings, and public/private identifier are all explanatory variables. Moreover, another variable was yield stability (significant at the 10 percent level), which combines both weather and variety characteristics like resistance. Notably the study was conducted at a time when public varieties accounted for 85 percent of acres planted in Kansas. Duvick and Cassman [6] similarly determined that both yield and yield stability drive corn hybrid variety selection in the central USA and Musser and Patrick [12, page 544] in a survey article found that just over one third of cotton and corn farmers are unwilling to give up any (emphasis in original) of their current average to stabilize year to year yields.

In a more recent analysis of Kansas wheat variety selection decisions, Barkley and Peterson [13] applied portfolio analysis to determine if mixes of wheat seed varieties in Kansas would increase profits. The use of systematic selected seed mixes or "blends" there increased from nothing as recently as 1997 to 10 percent in 2006, reaching a high point of 15.2 percent in 2004. Their analysis indicates that state average yields could have increased by 2.87 (about 7\%) bushels an acre over a 13-year period. However, the varieties to include in an optimal blend must be selected using data and statistical information (such as provided from variety trials) rather than the typical choices based on "variety descriptions, intuition, and average yields...”.

Dahl, et al. [14] compared variety adoption decisions between Canadian and USA wheat farmers. Using results from the Tobit model (only slightly smaller than for the linear version although for the US stem rust was not a significant
TABLE 2: Results from substate disease resistance comparison of group means between public and private wheat varieties in the North East Kansas (2004-2008).

\begin{tabular}{lcccc}
\hline $\begin{array}{l}\text { Type of } \\
\text { disease }\end{array}$ & Ownership & $\begin{array}{c}\text { Number } \\
\text { of } \\
\text { varieties }\end{array}$ & Mean & $\begin{array}{c}\text { Statistical } \\
\text { significance of } \\
\text { difference in } \\
\text { group means } \\
\text { (at 5\%) }\end{array}$ \\
\hline BYD & Public & 27 & 6.1 & No \\
WSM & Private & 11 & 6.9 & No \\
SBM & Public & 30 & 6.4 & No \\
Leaf rust & Private & 15 & 5.9 & Yes \\
Stripe & Public & 29 & 1.6 & \\
rust & Private & 14 & 1.6 & No \\
PM & Public & 30 & 7.3 & No \\
\hline
\end{tabular}

(Source: Kansas Performance Tests with Winter Wheat varieties, 2004-2008. Reports of Progress 930, 947, 967, 982, and 999. Kansas State University, Manhattan). Note that disease resistance rankings range from 1-9, with 9 as the lowest resistance.

selection criteria) they found that leaf rust in the US and stem rust in Saskatchewan (the only of the three studied provinces for which a disease resistant variable was used) led to reductions in the share of acerage planted of a variety. The marginal effects (1999, Table 3) are far stronger in Canada where a one-point decline in stem rust resistance (on a three point scale) reduced the acreage planted share by 18 percent, but only 0.88 percent in North Dakota. Conversely, USA farmers rate relative yield 10 times over what is done in Canada. Finally, USA farmers prefer public varieties to private ones by three to one; typically private varieties had lower end use quality rankings. That variable is not included in the Canadian regressions. These results suggest that while disease resistance is important to US farmers, it is far less so, and relative yield much more so, than for the Canadian provinces analyzed. Care though must be used in evaluating these results for there are several notable differences in law and regulations between the countries. Canada imposes a "visually distinguishable" grain quality standard absent in the US which limits variety availability there; plant variety protection standards there are also higher, with similar results (see also [15]). Conversely, in the US deficiency payments are a large issue with a bias to yields of lower quality wheats while a scab outbreak there late in the data analysis period likely made those farmers more cognizant of the importance of disease resistance.

While the recent domestic literature on wheat varietal selection criteria is limited, the available studies do confirm that farmers place most selection attention on yield. Disease resistance is a selection criterion as well, but typically only one of several components of yield stability. That factor 
TABLE 3: Results from substate disease resistance comparison of group means between public and private wheat varieties in the South East Kansas (2004-2008).

\begin{tabular}{lcccc}
\hline $\begin{array}{l}\text { Type of } \\
\text { disease }\end{array}$ & Ownership & $\begin{array}{c}\text { Number } \\
\text { of } \\
\text { varieties }\end{array}$ & Mean & $\begin{array}{c}\text { Statistical } \\
\text { significance of } \\
\text { difference in } \\
\text { group means } \\
\text { (at 5\%) }\end{array}$ \\
\hline BYD & Public & 24 & 6.0 & No \\
WSM & Private & 10 & 6.8 & No \\
SBM & Public & 27 & 6.1 & No \\
Leaf rust & Private & 13 & 5.8 & Yes \\
Stripe & Private & 26 & 1.6 & \\
rust & Private & 12 & 1.4 & No \\
PM & Public & 27 & 6.3 & No \\
\hline
\end{tabular}

(Source: Kansas Performance Tests with Winter Wheat varieties, 2004-2008. Reports of Progress 930, 947, 967, 982, and 999. Kansas State University, Manhattan). Note that disease resistance rankings range from 1-9, with 9 as the lowest resistance.

TABLE 4: Results from statewide disease resistance comparison of group means between public and private wheat varieties in Texas (2006-2007).

\begin{tabular}{lcccc}
\hline $\begin{array}{l}\text { Type of } \\
\text { disease }\end{array}$ & Ownership & $\begin{array}{c}\text { Number } \\
\text { of } \\
\text { varieties }\end{array}$ & Mean & $\begin{array}{c}\text { Statistical } \\
\text { significance of } \\
\text { difference in } \\
\text { group means } \\
\text { (at 5\%) }\end{array}$ \\
\hline PM & Public & 33 & 4.2 & No \\
Stripe & Private & 23 & 5.0 & \\
rust & Public & 39 & 5.7 & Yes \\
Leaf rust & Private & 84 & 4.5 & Public \\
& Private & 83 & 5.7 & No \\
\hline
\end{tabular}

(Source: Texas A\&M University, "Variety Testing Information") Note that the total number of public varieties under trial was 43 . However, in case of PM, for many public varieties resistance rankings were not reported and hence excluded from the analysis. Disease resistance rankings range from 19 , with 9 as the lowest resistance.

combined with the limited statistical data on yields and yield variability used by most farmers means that breeders have some latitude in minimizing disease resistance in a breeding program in favor of average yields. This study evaluates not the absolute levels of attention to disease resistance as a breeding characteristic but rather any relative differences between public and private sector varieties.

\section{Methodology and Data}

3.1. Disease Resistance Ranks. The validity of this analysis depends heavily on the published disease resistance rankings so it is important to have some understanding of how those rankings are developed and reported. The rankings used here are all on a 1-9 scale (9 the lowest resistance). Rankings reported on a 1-5 scale are interpolated to the 1-9 ranking, something which is widely done by pathologists even if lacking a strict systematic justification (Personal communication, Professor Mark Sorrels, small grains breeder, Cornell University). Disease rankings are initially set at the variety test field level in comparison with a reference variety of known susceptibility. Researchers sample the field to count the percent of affected plants and then assign a severity value compared to the reference variety. The two numbers are then multiplied together as a basis for the resistance rankings, which are then assigned [16]. There are several aspects of this approach which are relevant. First, the rankings can and do vary yearly as a result of the presence and virulence of a disease, which is affected by weather and other exogenous factors. However, because the rankings are relative to a reference variety which is also affected by disease, large annual variations in incidence are unlikely, which translate into small changes in the rankings. That is, a particular variety may in an absolute sense be moderately susceptible to a disease, but it is relatively the best available; if disease $x$ is present then the best choice is variety $y$ even if not as resistant to $x$ as a wheat farmer might hope for.

Second, while the data collection process is systematic, the assigning of rankings is inherently subjective. Third, a second subjective component is injected when the rankings from multiple trial locations combined into a single statewide value. A statewide value of course may over or understate resistance levels in any particular location. While these subjective aspects are potentially perplexing, there is no reason to believe that the ownership status (public or private) affects the outcome so no systematic bias is expected. The potential local versus statewide value bias can be partially assessed by doing analysis on substate areas where diseases are reported to be more or less problematic (see below).

3.2. Data Sources. Of the several state reports available, the one from Kansas is the most detailed. Resistance values for six individual diseases are provided over an eight-year period along with a description of the prevalent diseases for each year analyzed [17]. The initial part of our analysis utilizes the Kansas data for the six most common diseases. The analysis includes eight years of data to capture annual variations (2001-2008). Variations in resistance are not great compared to weather-affected yield studies, but they do occur. The second part of the analysis uses two-year data on wheat resistance rankings from Texas, but only a smaller number of diseases (three) are reported.

Only winter wheats (both hard and soft reds and a few whites) are reported in these two-state trials. Spring and Durham wheats which grow in different climatic areas with potentially different disease susceptibilities are therefore 
not included in our analysis and could lead to different conclusions.

A final data need is to categorize the varieties identified only by variety name as publically or privately owned. The GRIN (Germplasm Resources Information Network) data base contains accessions from public sector breeders (and some private as well) searchable by cultivar name for identifying the variety owner (search available at http://www.arsgrin.gov/npgs/acc/acc_queries.html. Last visited 3/16/11). Protected varieties, both public and private, can be searched, again by cultivar name, through the Plant Variety Protection Office data base for identifying ownership (search available at http://www.ars-grin.gov/cgi-bin/npgs/html/ pvplist.pl. Last visited 3/16/11). If a variety ownership could not be established the variety was excluded from the analysis (about 8 percent of the data file).

We use a two-tailed $t$-test to examine the equality of means of disease resistance rankings between private commercial and public sector varieties. The hypothesis we are testing here is whether on average private varieties are equally disease resistant as those from the public sector. Since a priori we are not sure whether private sector varieties are more or less resistant than public sector varieties, we test the equality of group means. We do the analysis using both statewide data (pooled data set over various years and regions), and regionspecific data within a state, wherever possible. Group mean comparison and testing of hypothesis is done for each disease separately. (We used STATA for the analysis.)

\section{Results}

4.1. Analysis of Resistance Data from Kansas. Results from the analysis of comparison of resistance rankings of public and private varieties from Kansas are presented in Table 1. In this analysis we focus on six diseases based on their economic importance to the farmers in the state [18]. The diseases we selected are barley yellow dwarf (BYD), wheat streak mosaic (WSM), soil borne mosaic (SBM), leaf rust, stripe rust, and powdery mildew. The varieties included in Table 1 represent 81.7 percent of planted acreage in Kansas and 10 of the leading 10 varieties [19]. Except for stripe rust and powdery mildew, the results of statewide analysis presented in Table 1 suggest that the disease resistance rankings are significantly different between public and private varieties, leading to rejecting the null hypothesis. Somewhat surprisingly to us, the results show that private varieties are more resistant in most cases.

The statewide analysis however risks a bias against public or private varieties if either group is targeted to a substate area where specific diseases are more or less virulent. In their recommendation to Kansas wheat farmers DeWolf et al. [4], note that, "Diseases and pests differ considerably in the magnitude of yield loss that they cause and in their prevalence across the state. Therefore, it is important to consider regionally important diseases and pests when selecting wheat varieties." In order to address this potential local versus statewide value bias, we conducted a substate analysis with focus on the North East Kansas and the South East Kansas.
However, note should be taken that the disease ratings are presented for the entire state and hence do not necessarily reflect the ratings for any particular subarea. For that reason, we direct readers to the entire disease rating report available from Kansas State University [17]. For the five years, for which the data are available [17], the North East was relatively disease-free compared to the South East where diseases such as BYD and leaf rust were reported to be more problematic in certain years, especially 2006, 2005, and 2004 (Kansas Wheat Performance Tests reports). Results presented in Tables 2 and 3 show a similar trend (private varieties are more resistant albeit not statistically significant) as in Table 1, implying that there is no local versus statewide bias in resistance rankings.

4.2. Analysis of Resistance Data from Texas. Results from the group mean comparison of disease resistance rankings of public and private varieties from Texas are reported in Table 4. We could access data for two years (2006-2007) only and for three diseases: powdery mildew (PM), stripe rust, and leaf rust (Texas A\&M University). In the case of stripe rust, private varieties are more resistant than public ones at the one percent level. In the case of PM and leaf rust public varieties are slightly more resistant than private varieties, albeit not statistically significant. Results from the analysis using only two years of data from Texas therefore suggest a similar pattern as that from Kansas, that is, when there is statistically significant difference between disease resistance of private and public varieties, private varieties are more resistant.

\section{Conclusions}

Our analysis indicates that disease resistance of public and private wheat varieties is equal if indeed private varieties are not slightly more resistant, as measured using assigned relative resistance rankings. The analysis is based largely on data from a single state (Kansas) over eight years so the standard cautionary note of the need for additional state and years of data when those data become available applies here. The area planted by the included varieties represents more than 80 percent of wheat acres and all of the leading 10 varieties so that the representativeness of the analysis is good. However, using the available data an additional criticism of private breeding activates, that they are more susceptible to disease compared to public varieties, is found to have no statistical basis. We are unable to provide insights into the sustainability of this conclusion beyond a period when public breeders provide much of the resistant germplasm which is then incorporated into private varieties. A larger private breeding investment would seem to be called for which may or may not be forthcoming under private wheat seed production profitability. In general though it is the public sector not the private which invests in the lengthy and costly background or development breeding process to transfer resistance from germplasm collections to commercial varieties.

Our empirical conclusions are limited to the relatively dry states of Kansas and Texas, and to the winter wheats (both hard and soft reds) grown there. Results for damper 
regions where diseases may be more prevalent, as well as for spring and Durham wheats, which may have different disease susceptibilities as well, could be different. However as the results show the private sector is more effective than the public in incorporating disease resistance into commercial varieties when both use the same sources of disease resistance there is no inherent reason why the situation would differ for other regions or wheat types.

\section{References}

[1] D. E. Kolady and W. Lesser, "But are they meritorious? Genetic productivity gains under plant intellectual property rights," Journal of Agricultural Economics, vol. 60, no. 1, pp. 62-79, 2009.

[2] J. Walsh, "Genetic vulnerability down on the farm ( corn)," Science, vol. 214, no. 4517, pp. 161-164, 1981.

[3] D. N. Duvick, "Major united states crops in 1976," Annals of the New York Academy of Sciences, vol. 287, pp. 86-96, 1977.

[4] E. D. DeWolf and P. E. Sloderbeck, "Wheat Variety Disease and Insect Ratings 2008," Kansas State U Ag, Exp. Station, MF-991, 2008, http://www.oznet.ksu.edu/library/plant2/mf991.pdf.

[5] J. M. Alston and R. J. Venner, "The effects of the US Plant Variety Protection Act on wheat genetic improvement," Research Policy, vol. 31, no. 4, pp. 527-542, 2002.

[6] D. N. Duvick and K. G. Cassman, "Post-green revolution trends in yield potential of temperate maize in the northcentral United States," Crop Science, vol. 39, no. 6, pp. 16221630, 1999.

[7] B. L. Dahl, W. W. Wilson, and D. D. Johnson, "Valuing new varieties: Trade-offs between growers and end-users in wheat," Review of Agricultural Economics, vol. 26, no. 1, pp. 82-96, 2004.

[8] K. J. Frey, "National plan for genepool enrichment Of U.S. crops," National Plant Breeding Study-III, Special Report 101, Iowa State University, Ames, Iowa, USA, 1998.

[9] U.S. Congress, Office Technology Assessment, Pest Management Strategies in Crop Protection, Vol. I, 1979 http://www .fas.org/ota/reports/7912.pdf.

[10] Z. Griliches, "Hybrid corn: an exploration of the economics of technological change," in Technology, Education and Productivity: Early Papers with Notes to Subsequent Literature, pp. 27-52, Basil Blackwell, New York, NY, USA, 1988.

[11] A. P. Barkley and L. L. Porter, "The determinants of wheat variety selection in Kansas, 1974 to 1993," American Journal of Agricultural Economics, vol. 78, no. 1, pp. 202-211, 1996.

[12] W. N. Musser and G. F. Patrick, "How much does risk really matter to farmers?" in A Comprehensive Assessment of the Role of Risk in Agriculture, R. E. Just and R. D. Pope, Eds., chapter 24, pp. 537-556, Kluwer Academic, Dodrecht, The Netherlands, 2002.

[13] A. Barkley and H. H. Peterson, "Wheat variety selection: an application of portfolio theory to improve returns," in Proceedings of the NCCC-134 Conference on Applied Commodity Price Analysis, Forecasting, and Market Risk Management( '08), St. Louis, Mo, USA, 2008.

[14] B. L. Dahl, W. W. Wilson, and W. W. Wilson, "Factors affecting spring wheat variety choices: Comparisons between Canada and the United States," Canadian Journal of Agricultural Economics, vol. 47, no. 3, pp. 305-320, 1999.

[15] W. Lesser, "Canadian seeds act: do they mimic plant breeders' rights legislation?" Canadian Journal of Agricultural Economics, vol. 36, pp. 519-529, 1988.
[16] L. Cadle-Davidson, M. E. Sorrells, S. M. Gray, and G. C. Bergstrom, "Identification of small grains genotypes resistant to Wheat spindle streak mosaic virus," Plant Disease, vol. 90, no. 8, pp. 1045-1050, 2006.

[17] "Kansas State University, Kansas Performance Tests with Winter Wheat Varieties," Reports of Progress 930, 947, 967, 982, 999 and 1018, Manhattan, 2004-2008, http://www.agronomy .ksu.edu/extension/p.aspx?tabid=92.

[18] J. A. Appel, E. D. DeWolf, W. W. Backus, R. L. Bowden, and T. Todd, "Kansas Cooperative Plant Disease Survey Report: Preliminary 2008 Kansas wWheat Disease Loss Estimates," 2008, http://www.ksda.gov/includes/document_center/plant_ protection/Plant_Disease_Reports/2009KSWheatDiseaseLossEstimates.pdf.

[19] Kansas Department Agriculture, Division Statistics," "Wheat Variety," 2008, http://www.nass.usda.gov/Statistics_by_State/ Kansas/Publications/Crops/Whtvar/whtvar08.pdf. 


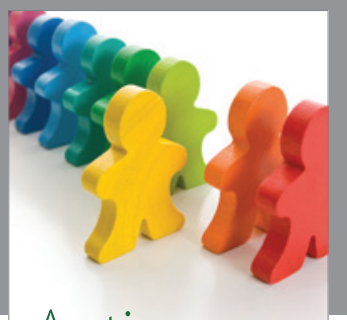

Autism

Research and Treatment
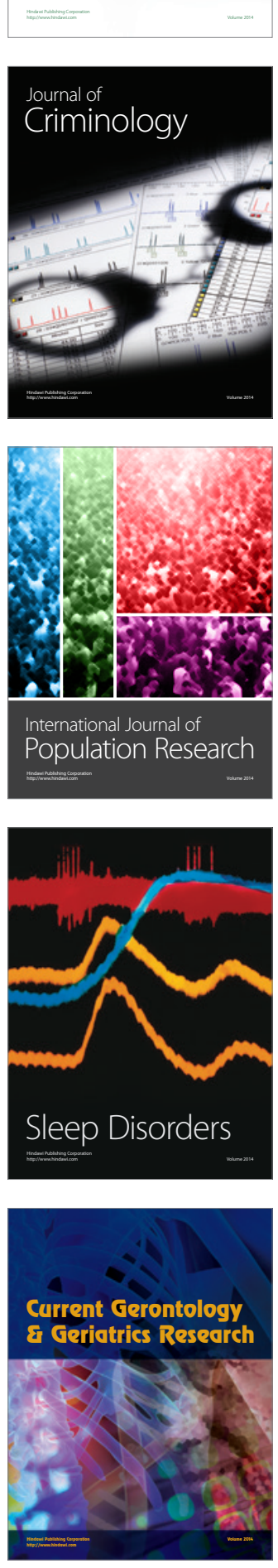
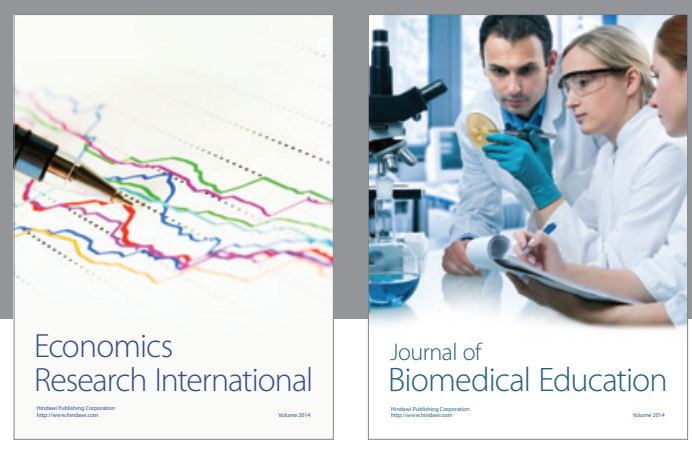

Journal of

Biomedical Education

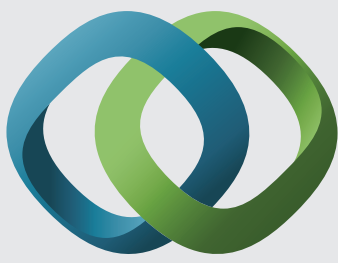

\section{Hindawi}

Submit your manuscripts at

http://www.hindawi.com
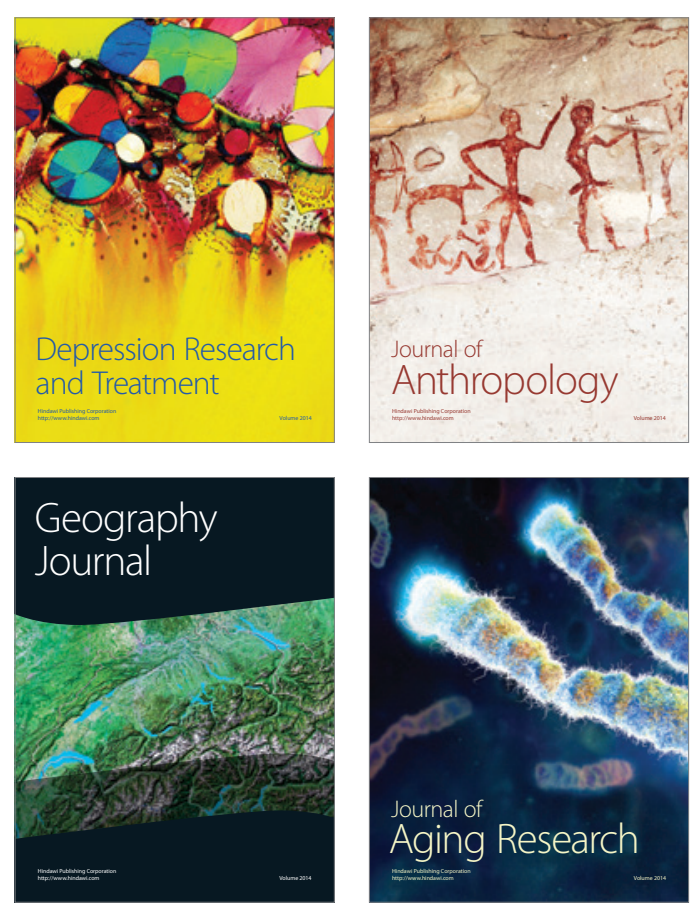

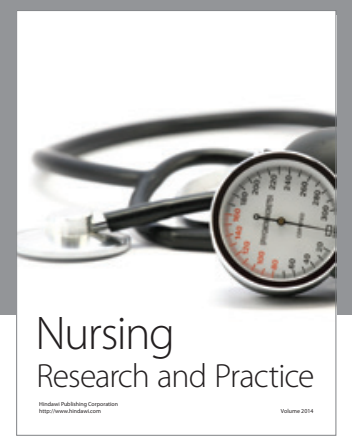

Nursing

Research and Practice

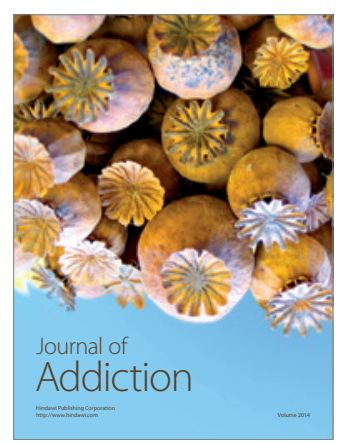

Child Development

Research

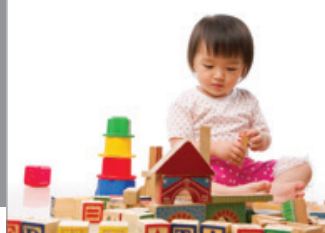

迥
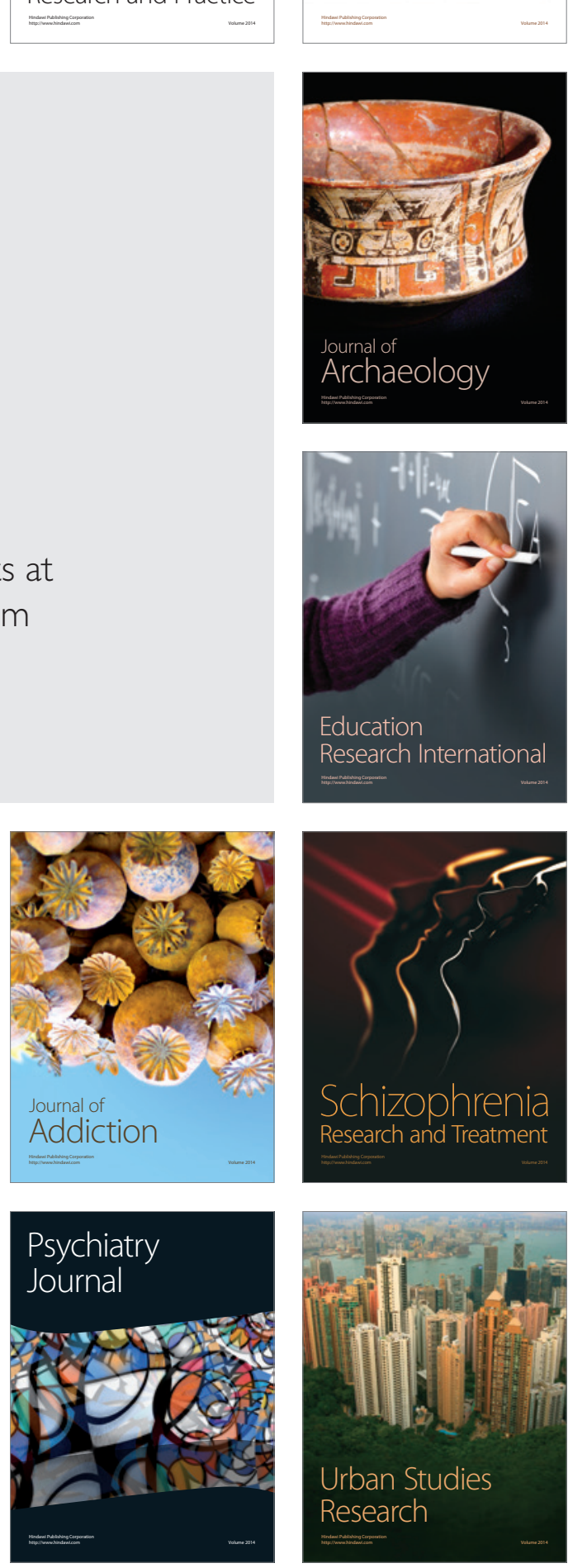